\title{
Control strategy for wayside supercapacitor energy storage system in railway transit network
}

\author{
Zongyu GAO ( $₫)$, Jianjun FANG, Yinong ZHANG, \\ Di SUN
}

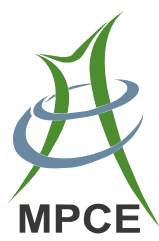

\begin{abstract}
This paper discusses the control strategy for energy management in railway transit network with wayside (substation) supercapacitor (SC) energy storage system (ESS). Firstly, the structure of the wayside energy storage system is introduced. Secondly, the model of energy storage system is built and the control strategy is described. Thirdly, in order to estimate the required energy storage system, a useful method is proposed to predict the instantaneous regenerative energy magnitude which is delivered to each substation. Finally, the ESS configuration for each substation is determined. A simplified mathematical model of the whole metro network is established and the main features of the control strategy are developed. Numerical simulations show the efficacy of suggested control strategy and the energy saving obtained for railway transit network.
\end{abstract}

Keywords Supercapacitor (SC), Energy storage system (ESS), Regeneration failure, Control strategy, Railway transit network

\section{Introduction}

Now, the clean energy and energy saving have become the hot topics of social development. Urban mass transit has

CrossCheck date: 22 May 2014

Received: 21 January 2014/ Accepted: 22 May 2014/Published online: 22 June 2014

(C) The Author(s) 2014. This article is published with open access at Springerlink.com

Z. GAO, J. FANG, Y. ZHANG, D. SUN, College of Automation of Beijing Union University, Beijing 100101, China

( $₫)$ e-mail: zdhtzongyu@buu.edu.cn

Z. GAO, School of Electrical Engineering, Beijing Jiaotong

University, Beijing 100044, China attracted more and more attentions, due to its advantages of environmental protection and energy saving. With the rapid development of power electronics, regenerative braking have been widely used in the railway transit network [1]. Regenerative braking energy can be absorbed by the other train in some timing, the can further reduce energy consumption and improver the energy-saving efficiency [2-4]. In PSCAD software environment a railway transit network model is built in [5], regenerative current value is simulated in each substation, and has deployed the supercapacitor (SC) in accordance with the capacity and the economic evaluation; In the Matlab environment urban rail traction power supply is simulated and the capacity configuration and energy saving are analyzed in [6]. In [7] and [8], through applying the ESS, the electrical train have been as a useful public transportation that their efficiencies can be improved. However, ESS sizing and network modeling have not been discussed. In [9], different mechanical and electrical techniques have been discussed in order to improve the energy efficiency in electrical railway systems. Some investigations have been done about the advantages of the on-board ESS in both electrically $[10,11]$ and diesel trains $[12,13]$. Advantages of using different ESS for both on-board and wayside system have been discussed in [14], but the control algorithm and equipment sizing have not been discussed. Quasi-static backwards looking method has been used for simulation of energy consumption of the train in [15]. As [16], stationary ESS has been used to save the regenerative energy. Stationary ESS has been proposed for voltage regulation of weak points in [17]. But, the metro network has not been modeled. Maximum regenerative energy of each station depends on the energy consumption of the auxiliary equipment, resistive forces, traffic conditions, and energy exchange between trains $[2,18]$.

In order to avoid regeneration failure and reduce energy consumption in railway transit network. The power supply 


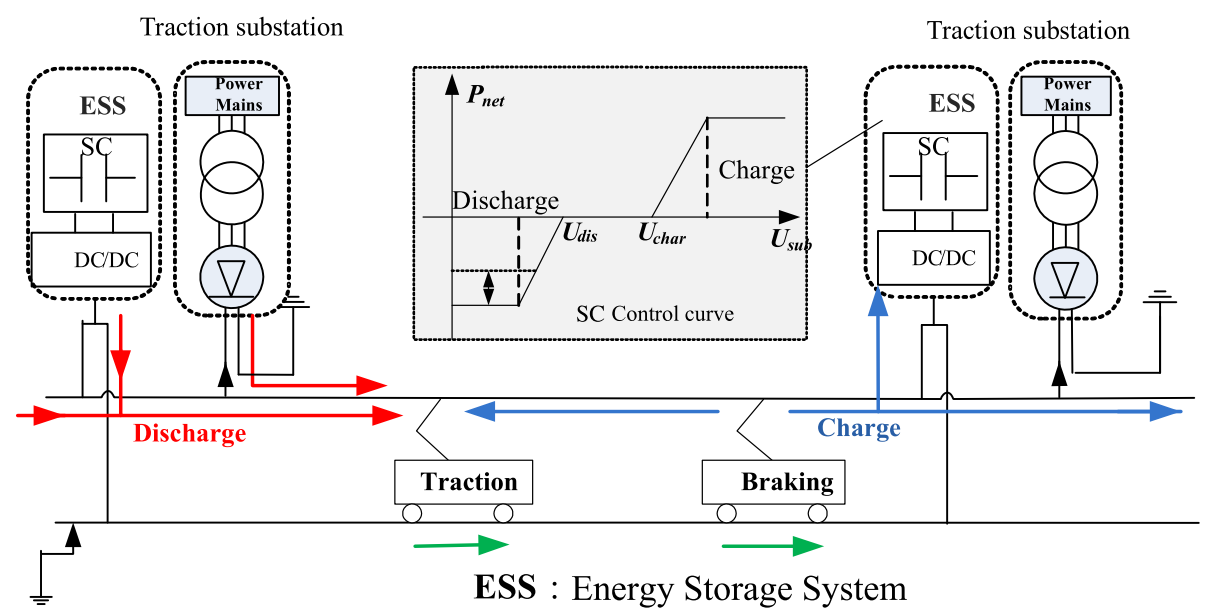

Fig. 1 Vehicle network traction characteristic
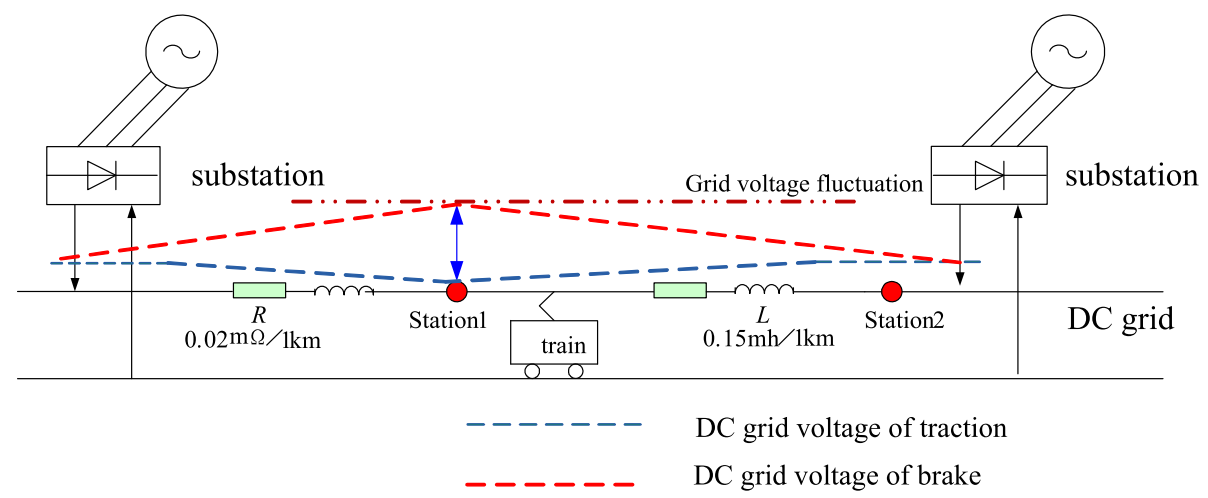

Fig. 2 Voltage fluctuation of DC system

model is built and the control strategy for energy management in railway transit network with wayside SC is presented.

The characteristic curves of the vehicle, substation and SC are studied, and their relationship is analyzed. The new control method for the energy storage system was proposed based on the power distribution between the SC, vehicle and the substation. Compared with [5], the new control strategy and the model are dynamic and real time, the simulation model is more comprehensive and detailed. This strategy has a good effect in containing voltage fluctuation, preventing the failure of regenerative braking. Simulation and experimental results have showed the feasibility of the method.

\section{Characteristics of network and control strategy}

Figure 1 shows the constitute of railway vehicle with power supply, including ESS, power mains, discharge and charge. From this figure, we know the flow direction of current with charge and discharger, and know the character

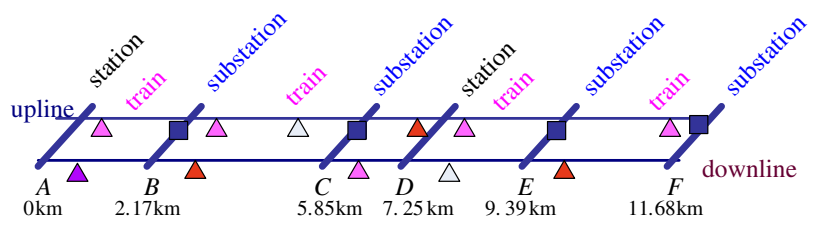

substation $\triangle:$ Train (powering) $\triangle:$ Train (coasting) $\triangle:$ Train (braking)

Fig. 3 Sketch of a domestic metro line

of SC control curve. Motor control states can be divided into three modes. When powering, the traction motor absorbs energy from the feeder line, lead to the voltage drop; when braking, the motor as generator and feeds energy to the feeder, leading to voltage rise. The voltage fluctuation significantly affect the characteristic of the train running [19]. In this paper, the data of used for the study is based on the real measurements of Beijing Metro Line 5 and is demonstrated in Fig. 2. The figure shows the details of driving cycle between two stations. Figure 3 shows the running character of the whole line. The maximum speed is $80 \mathrm{~km} / \mathrm{h}$ during acceleration and the maximum acceleration is $1 \mathrm{~m} / \mathrm{s}^{2}$. 


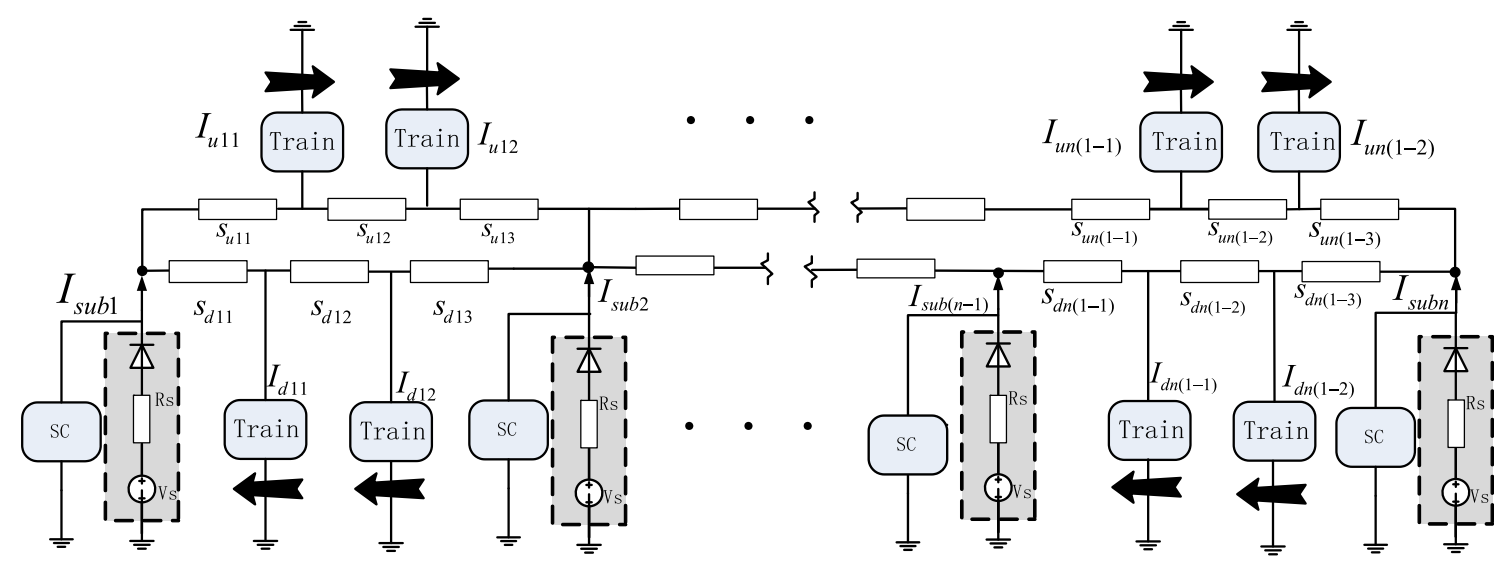

Fig. 4 Modeling of the metro network

The railway transit network model includes trains, unidirectional substations, ESS, and connecting lines, as shown in Fig. 4. Substations are modeled as ideal DC voltage sources. The connecting lines are modeled as electric resistances. Since the trains are moving between these stations, the resistance among the train, the starting station and the next station is time variant. Therefore, for each time point, these values was calculated as

$R^{\prime}=k * x(t) / 1000$

$R^{\prime \prime}=k *(d-x(t)) / 1000$

where $R^{\prime}$ is the line resistance between the train and the last station $(\Omega / \mathrm{km}) ; R^{\prime \prime}$ is the grid resistance between the train and the next station $(\Omega / \mathrm{km}) ; k$ is the resistive coefficient, the value is set to $0.019 \Omega / \mathrm{km} ; d$ is the distance between the start and next stations; $x(t)$ is the distance between the train and start station. In simulation environment, the value of resistors can change during the simulation. The network model includes all 24 stations of the Line 5 as a sample.

\subsection{Substation model}

Traction substation is the uncontrolled rectifier, the current is unidirectional [20]. The traction substation model with $\mathrm{SC}$ is shown in Fig. 5, Line $R_{\mathrm{S}}$ is line impedance. Switch S1 is closed when substation output current is forward direction. Switch S1 is opened when substation output current is negative. In order to model SC charged, substation parallel connection a braking resistor. Switch S2 closed during $V_{\text {sub }} \geq U_{\text {char }}$, analog SC charging. Switch S2 opened during $V_{\text {sub }} \leq U_{\text {char }}$, analog SC stopping charge. Through control the closed and open of S2, the remaining energy flowing is controlled between SC with DC line network. Line network voltage is uprised when emerging renewable brake energy, when line network voltage under $U_{c h a r}$, the energy is absorbed by adjacent train. When line

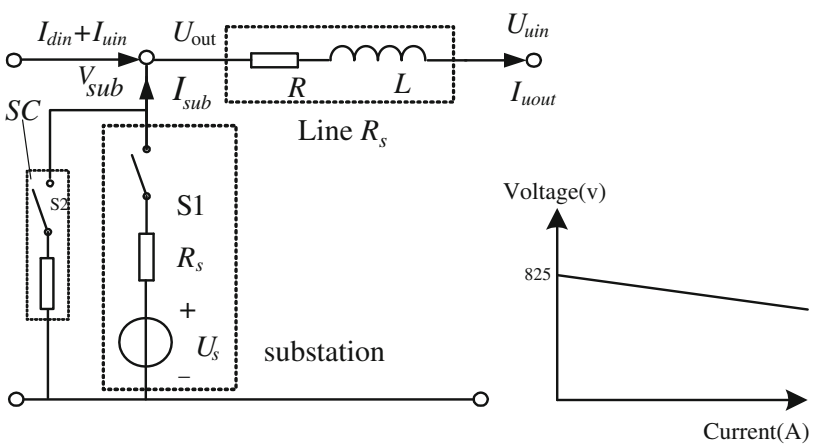

Fig. 5 Traction substation model with SC

network voltage exceeded $U_{\text {char }}$, some renewable energy is absorbed by adjacent train, the remaining renewable energy is absorbed by SC. $I_{r}$ is renewable current when $I_{\text {sub }}$ is negative, the remaining renewable power of substation is $P_{r}=U_{\text {out }} I_{r e}$, the remaining renewable energy is $E_{r}=\int P_{r} \mathrm{~d} t . P_{r}$ and $E_{r}$ is an important factor for the SC configuration.

\subsection{Control strategy}

In the wayside SC energy storage system (SESS) control, the charging and discharging currents are given according to the changes of the feeder line voltage. When grid network is high voltage, SC absorbs current; when low voltage, $\mathrm{SC}$ releases energy to DC link. Not to consider the weight and size restrictions of SC, The large capacity for the $\mathrm{SC}$ can be chosen to stabilize the whole line network voltage. Energy management of wayside SC system gives more consideration to network. When the train is accelerating, the energy system outputs energy to suppress the voltage fluctuate of the pantograph voltage fall and improve the acceleration characteristics. When train 


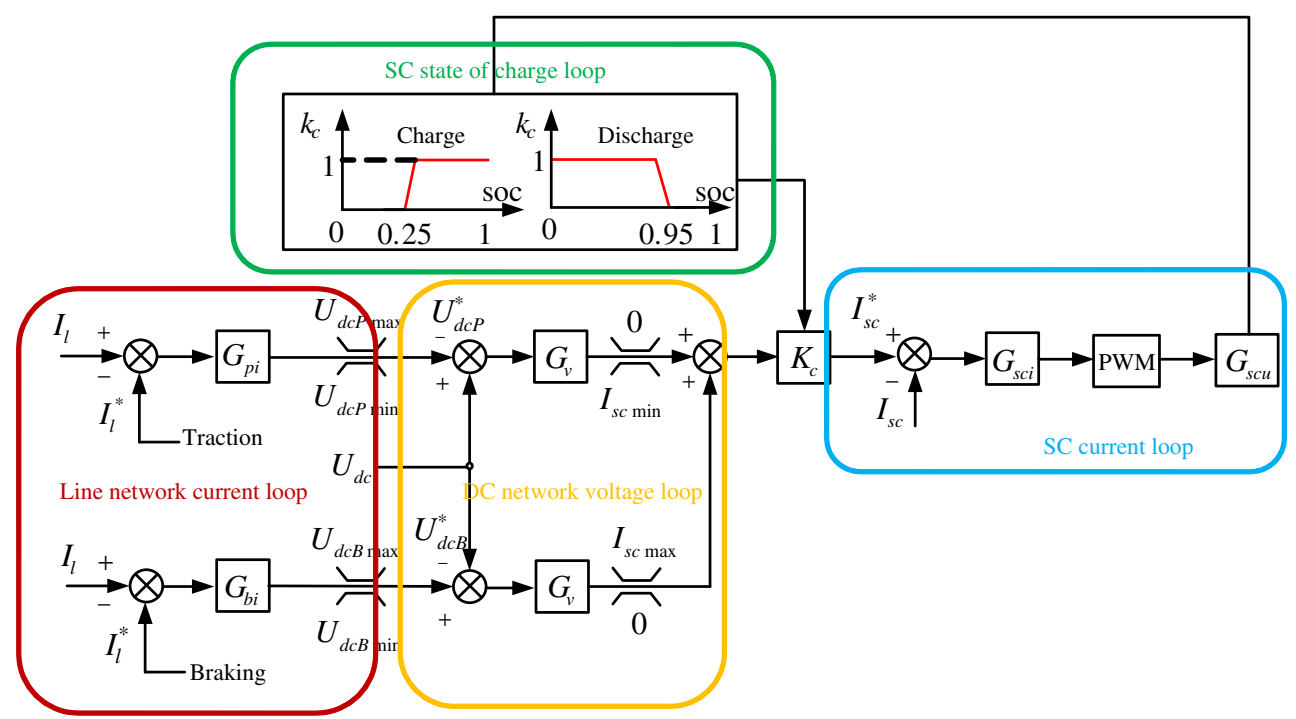

Fig. 6 Power distribution control strategy

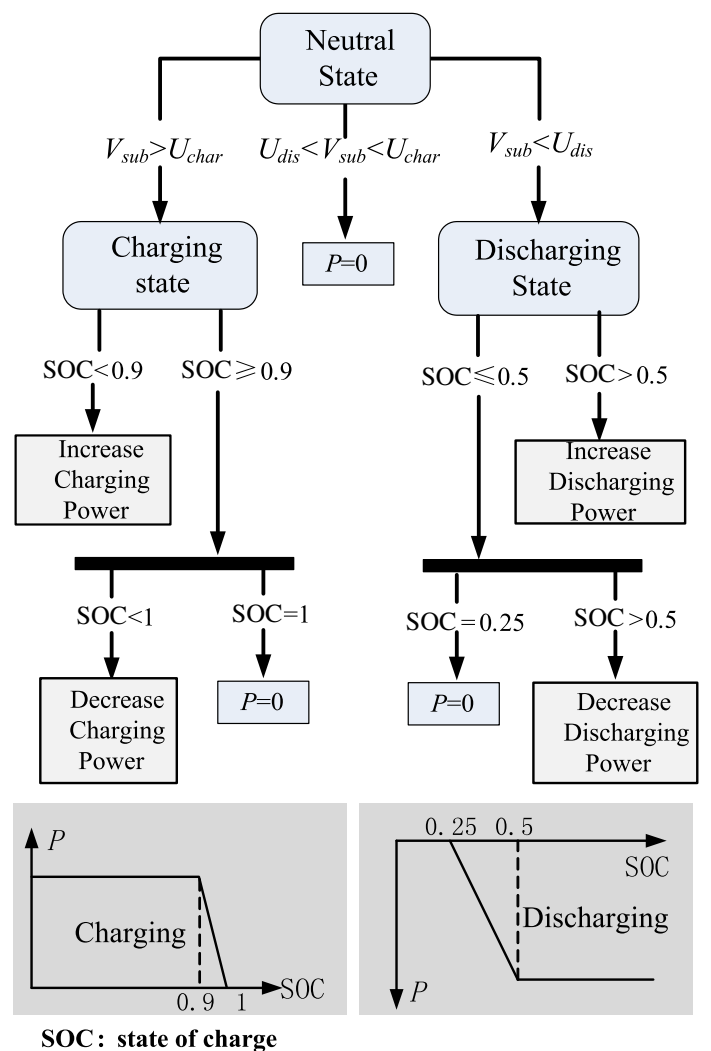

Fig. 7 Control algorithm diagram of wayside SC storage system

braking, the system absorbs braking energy for prevent the voltage fluctuate of the pantograph and at the same time preventing the regeneration failure, and improve the electrical braking performance. Based on the power distribution curve between the SC and the substation, this paper
Table 1 Parameters of simulation platform

\begin{tabular}{ll}
\hline Rate power & $2,000 \mathrm{~kW}$ \\
DC-link voltage & $1,500 \mathrm{~V}$ \\
Powering voltage action range & $1,100-1,300 \mathrm{~V}$ \\
Braking voltage action range & $1,600-1,800 \mathrm{~V}$ \\
Train gand-up & $3 \mathrm{M} 3 \mathrm{~T}$ \\
Control mode & $\mathrm{VVVF}$ inverter $1 \mathrm{C} 2 \mathrm{M}$ \\
Steel rail resistance & $0.009 \Omega / \mathrm{km}$ \\
Pantograph resistance & $0.015 \Omega$ \\
\hline
\end{tabular}

proposes a control strategy for the energy storage system, as shown in Fig. 6.

Show as Fig. $6, U_{d c}{ }^{*}$ is given through the line current. Indetail $U_{d c}{ }^{*}$ is given through comparing the line current with a reference line current. Through think about the logical conditions, SC energy storage system can take actions according to the energy management strategy designed.

A current loop is added and many benefits are gained. Firstly, it can avoid unwanted inflow and outflow between the SC and the feeder line. Secondly, it can decide the voltage dynamic value and the static value. Thirdly, it can decide the power distribution of the power between the feeder line and the SC.

The control algorithm flow chart is shown in Fig. 7. In the control strategy, when SOC $<0.9$, charge through constant high power; when $\mathrm{SOC}=0.9$, reduce the charging power; when $\mathrm{SOC}=1$, stop charging during discharging; when $\mathrm{SOC}>0.5$, discharge through constant high power; when $0.5>\mathrm{SOC}>0.25$, reduce the discharging power; when $\mathrm{SOC}=0.25$, stop discharging. 
Through SOC loop control, SC SOC value is kept in the range from 0.25 to 1 .

\section{Control simulation}

\subsection{Simulation parameters}

For test the feasibility of the control strategy, a model of substation installation SC is built by Matlab/Simulink software. Through this model, the whole working conditions of the system are considered. The model included powering, coasting and braking conditions. Table 1 is the parameters of simulation platform and Table 2 is the parameters of the SC.

\subsection{Simulation platform}

The new railway transit network with $\mathrm{SC}$ included three parts: urban rail vehicles; traction substation; SC energy storage system (SESS); SESS model structure is shown in Fig. 8. SESS includes three parts: input, output and simulation operation. Simulation operation includes train traction computing, power flow calculation and SC energy storage models.

Table 2 Parameters of SC

\begin{tabular}{ll}
\hline Cell & $V_{\max }=2.5 \mathrm{~V}$ \\
Total capacity & $48 \mathrm{~F}$ \\
Internal resistance & $0.2 \Omega$ \\
Energy & $5.1 \mathrm{kWh}$ \\
Maximum voltage & $1,000 \mathrm{~V}$ \\
\hline
\end{tabular}

This traction computing model includes route condition, train parameter and run map message. The route condition includes gradient and curve, i.e., substation parameters are the load of train, auxiliary power, traction and braking curve, run map provided station distribute message, run and stop times of the train. Through the model, the speed, the distance and the power can been obtained.

\subsection{Simulation results}

The variation of line currents and line voltage during the whole operation was shows in figure 9. When the train is accelerating, the DC line voltage drops. When the line current exceeds the limit value and the voltage drops below the action value $1,300 \mathrm{~V}$, the $\mathrm{SC}$ releases energy to the line network for reduce the line current and contain the voltage drop at the pantograph. Finally, the DC link voltage maintains at $1,200 \mathrm{~V}$. When the vehicle is coasting, SC energy storage system is in standby mode. When the vehicle is braking, the DC line voltage rises. When the

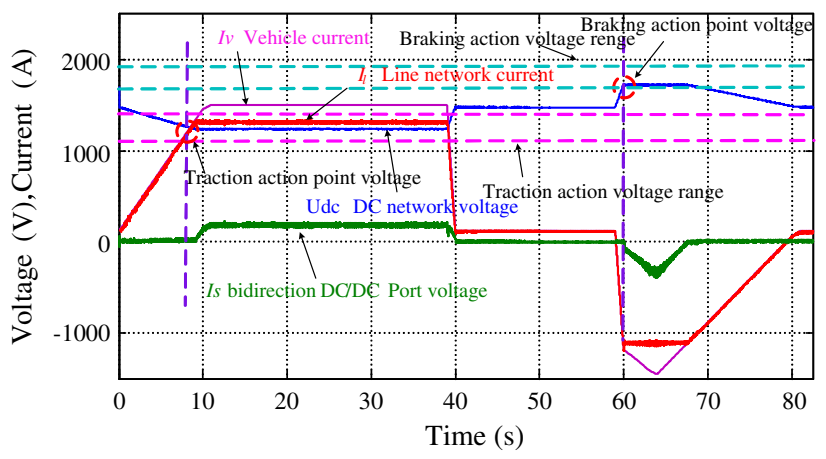

Fig. 9 Line currents and line voltages of substation

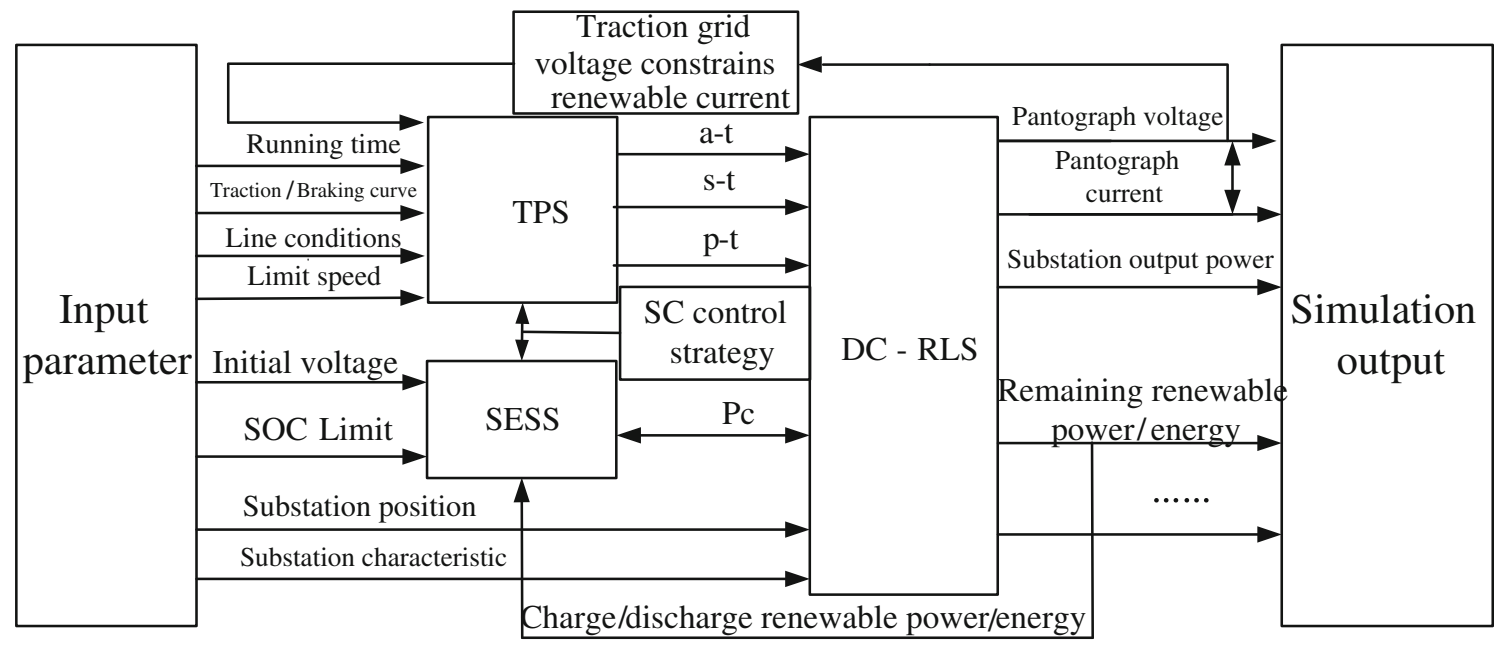

SESS : SC Engery Storage Simulatior TPS:Train Performance Simulatior DC - RLS: DC - Railway Loadflow Simulator

Fig. 8 Simulation model 


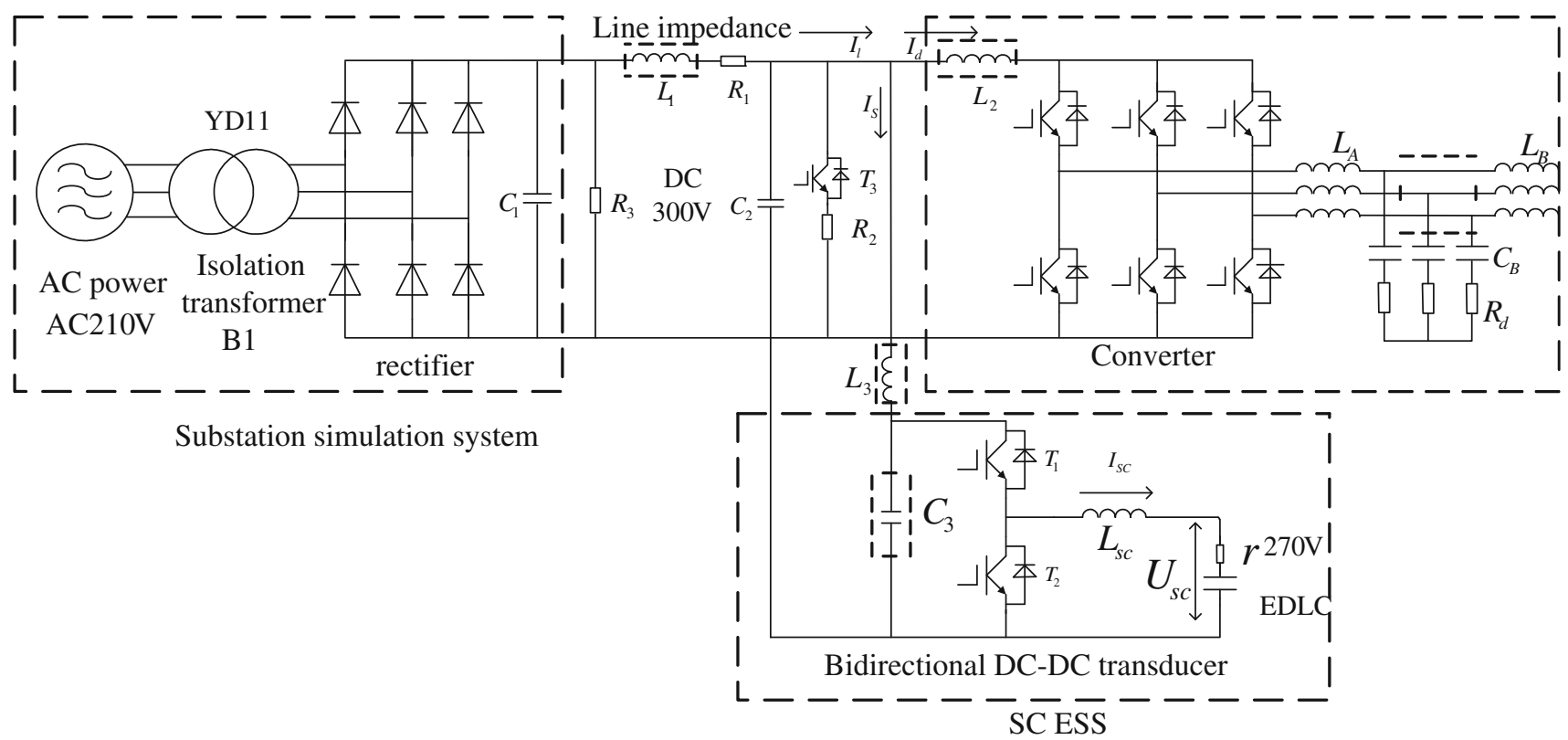

Fig. 10 Block diagram of $3 \mathrm{~kW} \mathrm{SC} \mathrm{platform}$

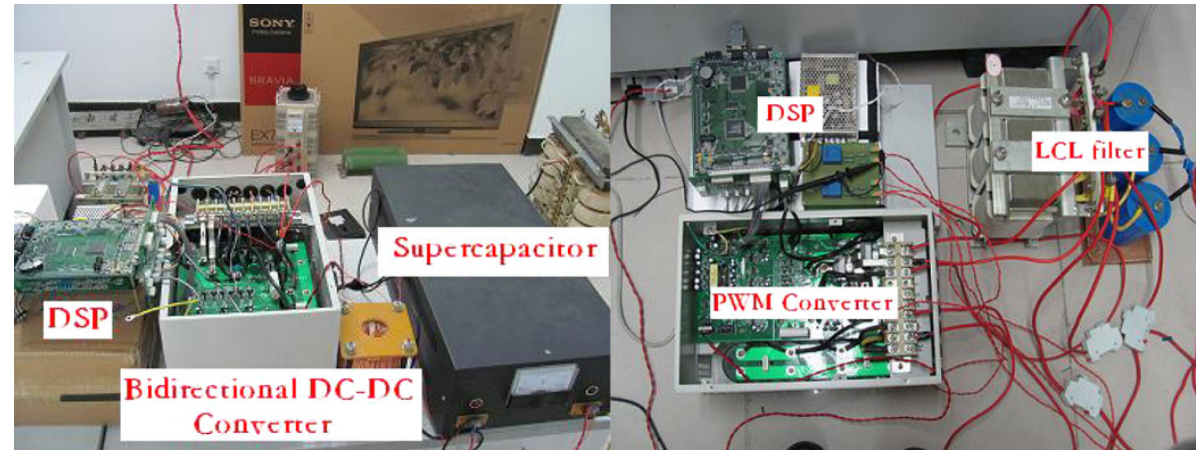

Fig. 11 Prototype of $3 \mathrm{~kW} \mathrm{SC} \mathrm{platform}$

braking current exceeds the limit value and the line voltage rises above the action value $1,700 \mathrm{~V}$, the $\mathrm{SC}$ absorbs regenerative braking current to contain the voltage rise at the pantograph and prevent the regeneration failure.

\section{Results of experiment}

\subsection{Experimental platform}

Based on the laboratory conditions, a $3 \mathrm{~kW} \mathrm{SC}$ experimental platform is built. Fig. 10 shows the circuit diagram of the experimental platform. The platform consists of substation simulation system, load simulation system, and SC energy storage system.

The substation simulation system converts $210 \mathrm{~V}$ AC to $300 \mathrm{~V} \mathrm{DC}$ through the diode rectifier. $210 \mathrm{~V} \mathrm{AC}$ is turned into $380 \mathrm{~V} \mathrm{AC}$ through an auto-regulator and a three-phase isolation transformer (ensure the vehicle simulation system and substation systems connecting to the grid at the same time). Load simulation system is realized by a PWM converter, whose current is fed back to the grid through LCL filter. PWM converter uses grid voltage oriented control method. The reference value $I_{d}$ is calculated according to the characteristics of the load. When the $I_{d}>0$, the PWM converter operates in rectifier state; when $I_{d}<0$, the PWM converter operates in inverter state.

The SC bank is the product of Beijing Supreme Power Systems Co. Ltd. Parameters are as follows: rate voltage $320 \mathrm{~V}$, capacity $1.5 \mathrm{~F}$ and internal resistance $2.75 \Omega$. The picture of experimental platform is shown in Fig. 11.

\subsection{Experimental results}

Figure 12 shows the simulation result of the pantograph currents and the voltages, through the "a" range of Fig. 12 


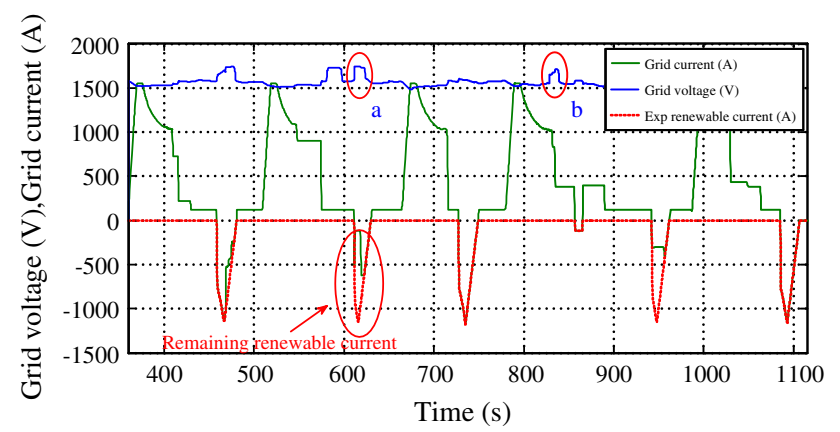

Fig. 12 Voltges and currents in pantograph

that the pantograph voltage is restrained on the value of $1,750 \mathrm{~V}$ during renewable braking, the remaining renewable current of SC is the D-value of expecting renewable current (red line) and grid current (green line). the " $b$ " shown that the action is entering into coasting. At the same time, only the SC can obtain the energy through DC supply network and energy consumption is low. but other substation is in the area of renewable brake and the pantograph voltage would rise because of the shortage of renewable load.

Figures 13-15 show the simulation results of different departure intervals for railway transit network, these figures show the results for the current and voltage of

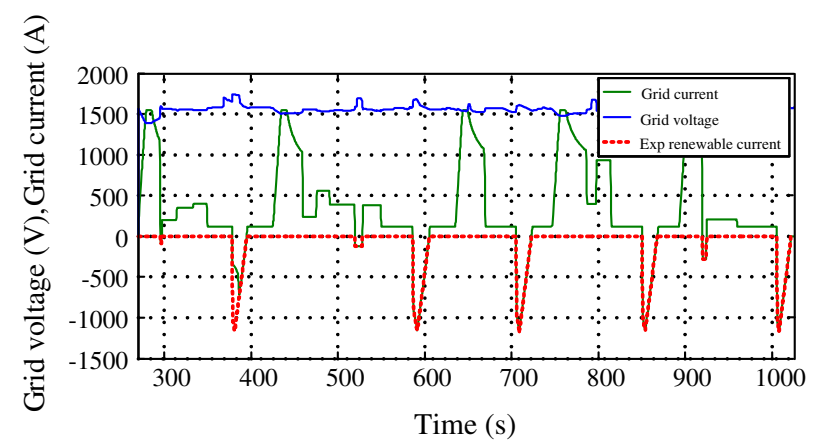

(a) substation voltage and current of upline

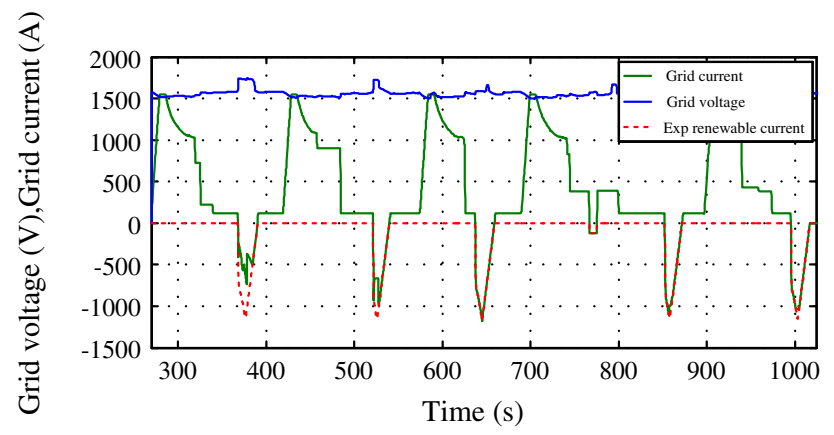

(c) substation voltage and current of downline substation, and remaining renewable energy and power when the DC supply network is running. Because the design goal of SC is to absorb remaining renewable energy, so the capacity of SC is decided by the biggest remaining renewable energy and power is decided by the biggest remaining power.

\subsection{Analysis of train remaining renewable energy and power}

Through previous simulation results, the remaining renewable energy and power can been obtained for different departure intervals. Figures 16-17 show that SC needs to absorb the smaller energy and power when the departure intervals are the shorter. At the same time, capacity configuration not only consider the highest speed but also need to consider multiple factors.

\subsection{ESS configuration}

The remaining renewable energy and the power can been obtained through simulation results, using BMOD0063P125 configuration capacity by series-parallel combination. Two constraint conditions need to be considered when the configuration SC banks:

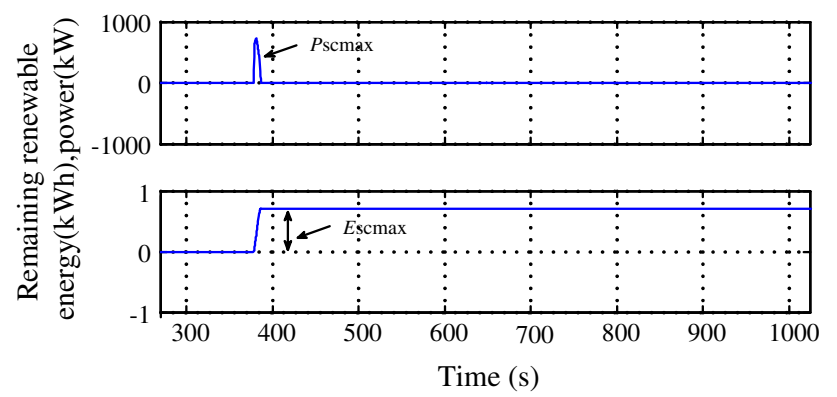

(b) upline remaining power and energy

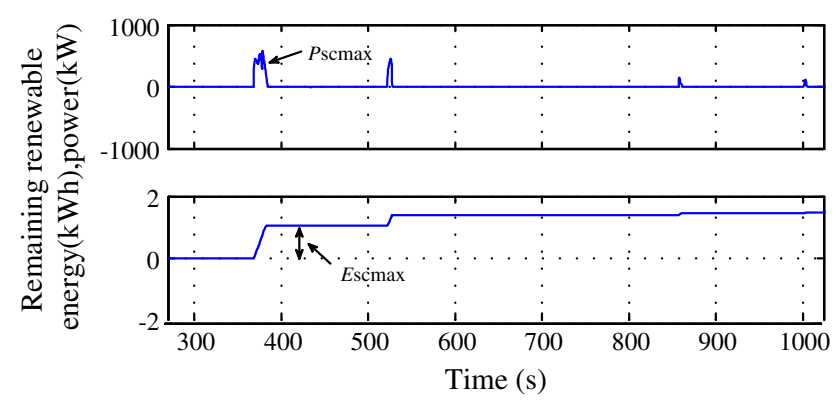

(d) downline remaining power and energy

Fig. 13 Wayside SC simulation results with headway $270 \mathrm{~s}$ 


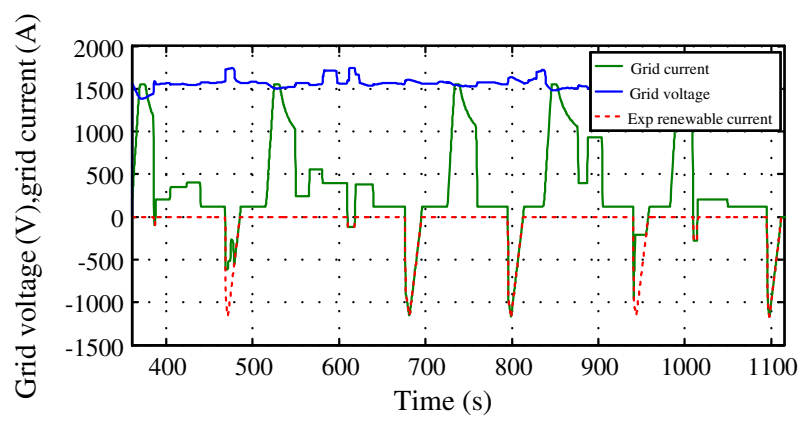

(a) substation voltage and current of upline

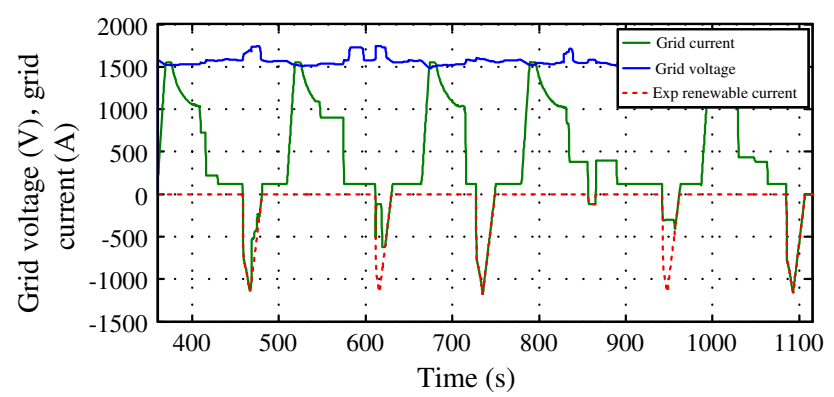

(c) Substation voltage and current of downline

Fig. 14 Wayside SC simulation results with headway $360 \mathrm{~s}$

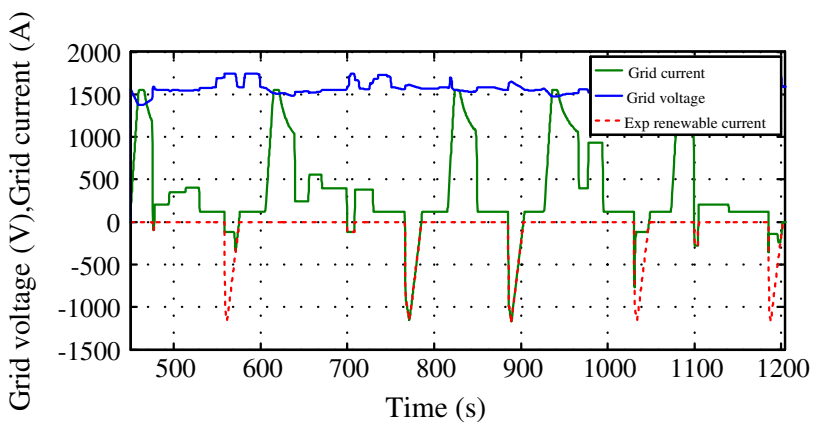

(a) substation voltage and current of upline

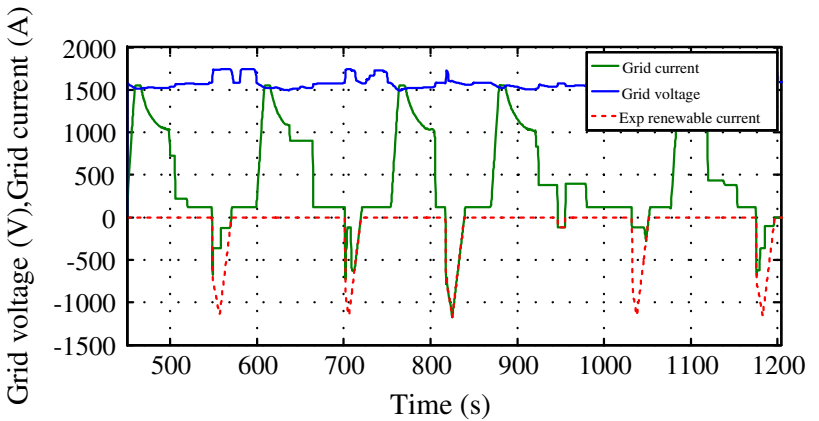

(c) substation voltage and current of downline

Fig. 15 Wayside SC simulation results with headway $450 \mathrm{~s}$

1) Because of SC self-characteristics that larger changes internal resistance and voltage of charge and discharge, this would impact the work efficiency of SC.

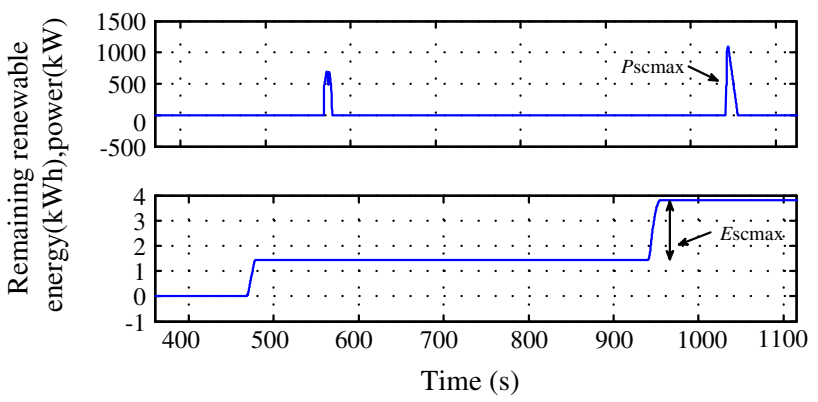

(b) upline remaining power and energy

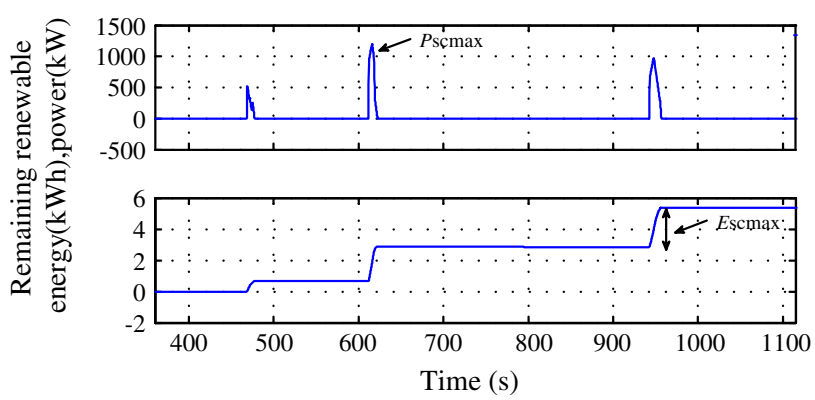

(d) Downline remaining power and energy

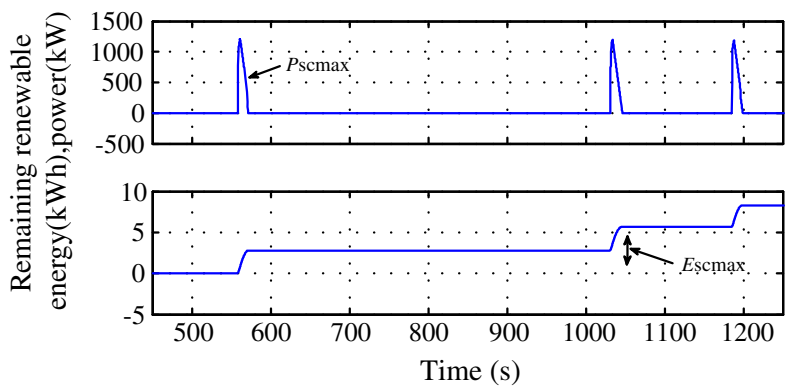

(b) upline remaining power and energy

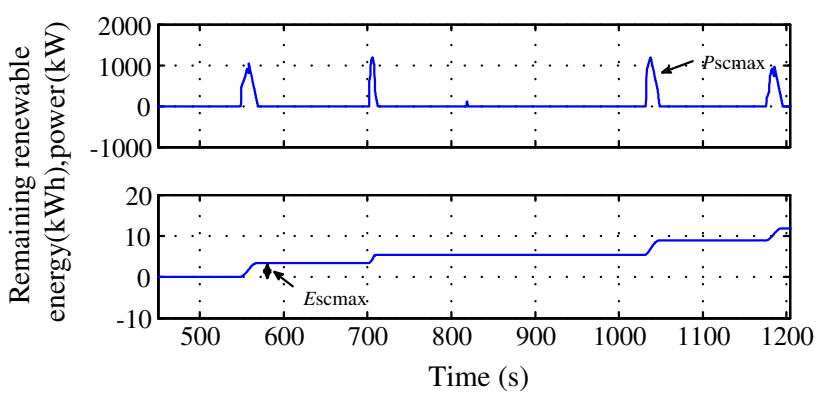

(d) downline remaining power and energy

The available energy of SC is $25 \%$ of former when the minimum discharge depth of SC is an half of the rated voltage. 


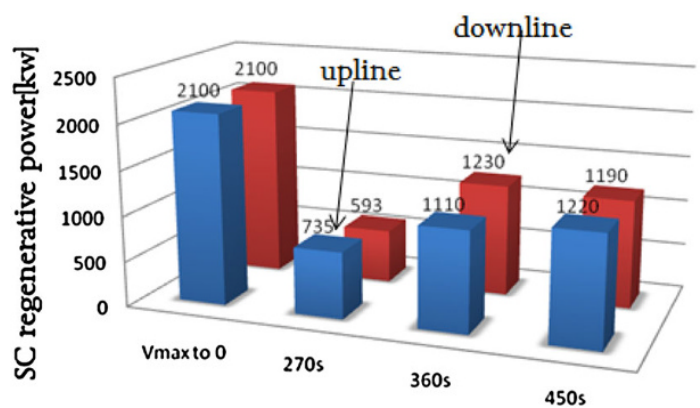

Fig. 16 Surplus regenerative power of wayside SC in different indeparture intervals

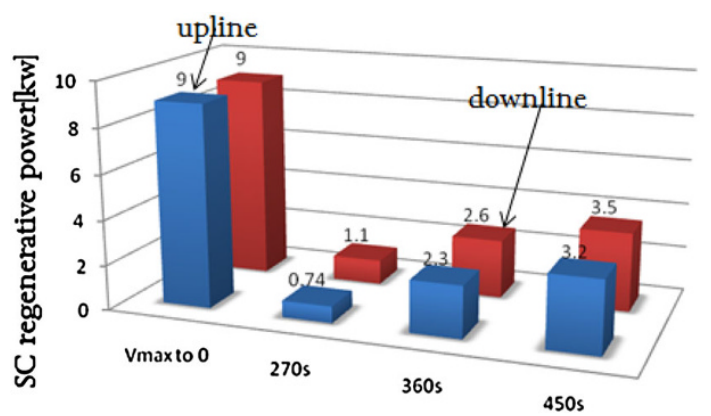

Fig. 17 Surplus regenerative energy of wayside SC in different indeparture intervals

2) Because of SC energy storage device and the supply network of DC $1,500 \mathrm{~V}$ in parallel, the DC/DC convertor work in boost state when SC discharges to DC supply network, the boost circuit step-up ratio is " 3 " based on references, and at this time the circuit is stable, so the minimum working voltage is $500 \mathrm{~V}$ $(1,500 / 3)$.

Through previous two constraint conditions, the series parallel configuration results of different departure intervals as shown in Table 3 .

\section{Conclusion}

In this paper, the supply network and the vehicle of the Beijing Metro Line 5 are modeled. Real data of metro line network are obtained from metro office. An efficient control strategy is proposed to obtain the maximum instantaneous regenerative energy of each station. Compared with other control strategy, the strategy has advantages of faster execution speed and smaller error because the energy storage device is in substation. Appropriate ESS configurations are proposed for different departure intervals. Finally, the simulation model and the experimental platform are set up. Simulation and experimental results verify
Table 3 The capacity configuration in different departure intervals

\begin{tabular}{lllll}
\hline Parameter & $\begin{array}{c}\text { Braking to stop } \\
\text { for one time }\end{array}$ & $\begin{array}{c}\text { Headway } \\
270 \mathrm{~s}\end{array}$ & $\begin{array}{l}\text { Headway } \\
360 \mathrm{~s}\end{array}$ & $\begin{array}{l}\text { Headway } \\
450 \mathrm{~s}\end{array}$ \\
\hline $\begin{array}{c}\text { Compound } \\
\text { mode }\end{array}$ & $\begin{array}{c}12 \text { series, } 4 \\
\text { parallel and } \\
2 \text { banks }\end{array}$ & $\begin{array}{c}7 \text { series } \\
\text { and } 2 \\
\text { banks }\end{array}$ & $\begin{array}{c}8 \text { series, } 2 \\
\text { parallel and } \\
2 \text { banks }\end{array}$ & $\begin{array}{c}10 \text { series, } 2 \\
\text { parallel and } \\
2 \text { banks }\end{array}$ \\
$\begin{array}{c}\text { Working } \\
\text { voltage } \\
(\mathrm{V})\end{array}$ & $750 \sim 1,500$ & $500 \sim 875$ & $500 \sim 1,000$ & $625 \sim 1,250$ \\
$\begin{array}{c}\text { Weight } \\
(\mathrm{kg})\end{array}$ & 5,566 & 847 & 1,936 & 2,904 \\
$\begin{array}{c}\text { Volume } \\
\left(\mathrm{m}^{3}\right)\end{array}$ & 6.444 & 0.98 & 2.24 & 3.36 \\
Storage & 9 & 1.04 & 2.6 & 3.5 \\
\hline
\end{tabular}

that the control strategy has a significant effect in suppressing the voltage fluctuation and preventing the regeneration failure.

Open Access This article is distributed under the terms of the Creative Commons Attribution License which permits any use, distribution, and reproduction in any medium, provided the original author(s) and the source are credited.

\section{References}

[1] Frohlich M, Klohr M, Rost J (2010) Energy storage on board of railway vehicle. In: Proceedings of the international exhibition and conference on power electronics, intelligent motion, power quality (PCIM Europe'10), Nuremberg, Germany, 4-6 May 2010, pp 391-397

[2] Barrero R, Van Mierlo J, Tackoen X (2008) Energy savings in public transport. IEEE Veh Technol Mag 3(3):26-36

[3] Ogasa M, Taguchi Y (2006) Power flow control of trolley hybrid electric vehicles. RTRI (Railway Technical Research Institute, Japan) Report 20(7):5-10

[4] Taguchi Y, Ogasa M, Hata $\mathrm{H}$ et al (2007) Simulation results of novel energy storage equipment series-connected to the traction inverter. In: Proceedings of the 13th European conference on power electronics and applications (EPE'07), Aalborg, Denmark, 2-5 Sept 2007, 9 pp

[5] Teymourfar R, Asaei B (2012) Stationary super-capacitor energy storage system to save regenerative braking energy in a metro line. Energy Convers Manag 56:206-214

[6] D’ Avanzo S, Iannuzzi D, Murolo F (2010) A sample application of supercapacitor storage systems for suburban transit. In: Proceedings of the international conference on electrical systems for aircraft, railway and ship propulsion (ESARS'10), Bologna, Italy, 19-21 Oct 2010, 7 pp

[7] Smith RA (2003) Railways: how they may contribute to a sustainable future. P I Mech Eng F 217(2):24-243

[8] Kamata S (2000) JR East takes up the challenge of searching for a railway that is kinder to the Earth. P I Mech Eng $\mathrm{F}$ 214(2):117-122

[9] Gunselmann W (2005) Technologies for increased energy efficiency in railway systems. In: Proceedings of the 11th European conference on power electronics and applications (EPE'05), Dresden, Germany, 11-14 Sept 2005, 10 pp

[10] Destraz B, Barrade P, Rufer A et al. (2007) Study and simulation of the energy balance of an urban transportation network. In: 
Proceedings of the 13th European conference on power electronics and applications (EPE'07), Aalborg, Denmark, 2-5 Sep 2007, $10 \mathrm{pp}$

[11] Steiner M, Scholten J (2005) Energy storage on board of railway vehicles. In: Proceedings of the 11th European conference on power electronics and applications (EPE'05), Dresden, Germany, 11-14 Sep 2005, 10 pp

[12] Hillmansen S, Roberts C (2007) Energy storage devices in hybrid railway vehicles: a kinematic analysis. P I Mech Eng F 221(1):135-143

[13] Akli1 CR, Roboam X, Sareni B et al (2007) Energy management and sizing of a hybrid locomotive. In: Proceedings of the 13th European conference on power electronics and applications (EPE'07), Aalborg, Denmark, 2-5 Sept 2007, 10 pp

[14] Foiadelli F, Roscia M, Zaninelli D (2006) Optimization of storage devices for regenerative braking energy in subway systems. In: Proceedings of the power engineering society general meeting (PES'06), Montreal, Canada, 18-22 Jun 2006, pp 18-22

[15] Van Mierlo J, Maggetto G (2001) Vehicle simulation program: a tool to evaluate hybrid power management strategies based on an innovative iteration algorithm. P I Mech Eng D 215(9):1043-1052

[16] Barrero R, Tackoen X, Van Mierlo J (2008) Quasi-static simulation method for evaluation of energy consumption in hybrid light rail vehicles. In: Proceedings of the IEEE vehicle power and propulsion conference (VPPC'08), Harbin, China, 3-5 Sep 2008, 7 pp

[17] Barrero R, Van Mierlo J (2010) Stationary or onboard energy storage systems for energy consumption reduction in a metro network. P I Mech Eng F 224(3):207-215

[18] Teymourfar R, Asaei B, Iman-Eini H (2012) Stationary supercapacitor energy storage system to save regenerative braking energy in a metro line. Energ Convers Manag 56:206-214

[19] Rufer A (2010) Energy storage for railway systems, energy recovery and vehicle autonomy in Europe. In: Proceedings of the international power electronics conference (IPEC'10), Sapporo, Japan, 21-24 Jun 2010, pp 3124-3127

[20] Steiner M, Klohr M, Pagiela S (2007) Energy storage system with ultracaps on board of railway vehicles. In: Proceedings of the 13th European conference on power electronics and applications (EPE'07), Aalborg, Denmark, 2-5 Sep 2007, 10 pp

Zongyu GAO received the B.S and M.E degrees from the Lanzhou JiaoTong University Lanzhou, China, in 1998 and 2005, respectively. Received the Ph.D in Beijing university of technology Beijing, China, in 2010, now he is a lecturer of traffic engineering, at the same time, he is engaging in postdoctoral research in Beijing Jiaotong university. His current research focuses on optimization of power processing systems.

Jianjun FANG received his B.E and Ph.D degrees from Huazhong agricultural university and the China agricultural university in 1993 and 1998 respectively. His research interests focuses on robot energy saving system.

Yinong ZHANG received her B.E and M.E degree in Electrical engineering from the Beijing university of science and technology Beijing, China, in 1994 and 2001 respectively. Her research interests include Electric transmission and electric power electronic technology.

Di SUN received B.E. degree in Traffic Engineering from the Jilin University Changchun, China, in 2007; M.E. and Ph.D. degrees in Traffic Information Engineering and Control from the Jilin University, Changchun, China, in 2009 and 2012, respectively. Her research interests include artificial intelligence, traffic behavior analysis and intelligent transportation systems. 